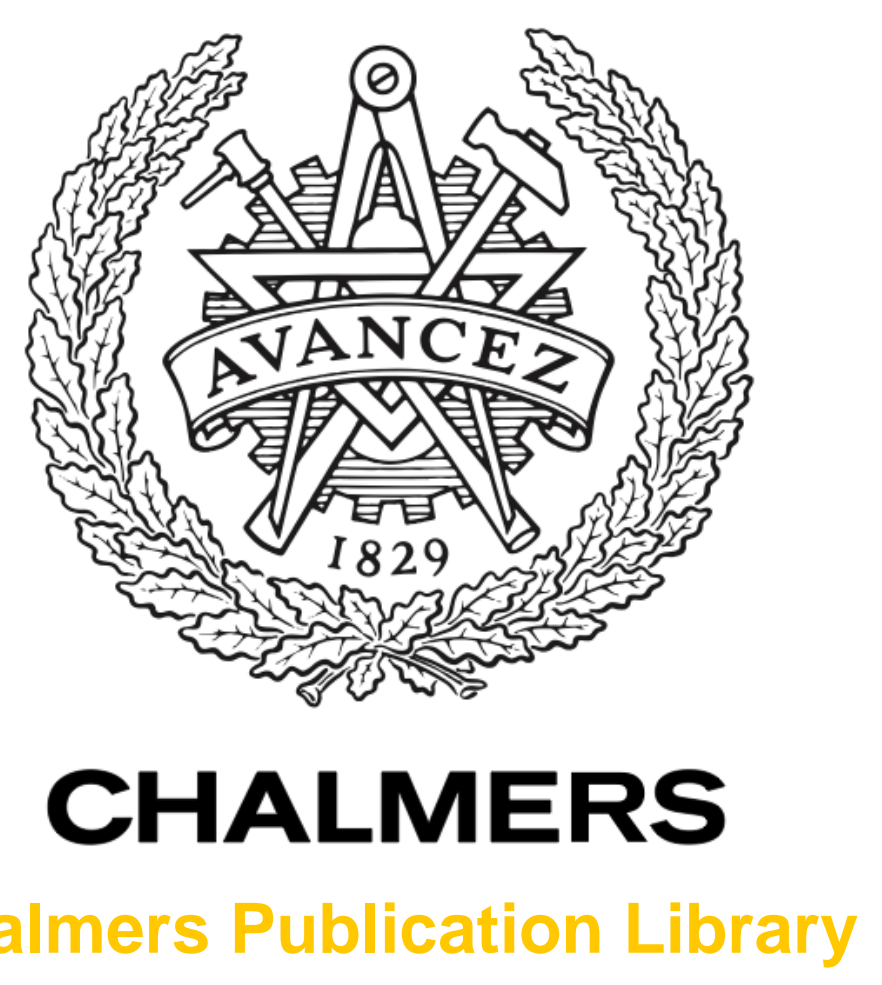

Chalmers Publication Library

Insights from guiding material development towards more sustainable products

This document has been downloaded from Chalmers Publication Library (CPL). It is the author's version of a work that was accepted for publication in:

International Journal of Sustainable Design (ISSN: 1743-8284)

Citation for the published paper:

Clancy, G. ; Fröling, M. ; Svanström, M. (2013) "Insights from guiding material

development towards more sustainable products". International Journal of Sustainable

Design, vol. 2(2), pp. 149-166.

http://dx.doi.org/10.1504/IJSDES.2013.057123

Downloaded from: http://publications.lib.chalmers.se/publication/176387

Notice: Changes introduced as a result of publishing processes such as copy-editing and formatting may not be reflected in this document. For a definitive version of this work, please refer to the published source. Please note that access to the published version might require a subscription. 


\title{
Insights from guiding material development towards more sustainable products
}

\author{
Gunilla Clancy*
}

Chemical Environmental Science, Chalmers University of Technology,

41296 Göteborg, Sweden

E-mail: clancy@chalmers.se

*Corresponding author

\section{Morgan Fröling}

Ecotechnology and Environmental Science,

Mid Sweden University,

83125 Östersund, Sweden

E-mail: morgan.froling@miun.se

\section{Magdalena Svanström}

Chemical Environmental Science, Chalmers University of Technology,

41296 Göteborg, Sweden

E-mail: magdalena.svanstrom@chalmers.se

\begin{abstract}
Faced with current challenges in society, many companies will need to develop more sustainable products in order to continue operations in the long term. Therefore, ways of identifying important sustainability considerations already in the early stages of material or product development are of importance. The article is based on action research in a material development project. The article provides a description of activities that were performed in the project in order to guide the material development process to enable more sustainable final products, reflections on the lessons learned from this project, and suggestions to similar projects in the form of an overall process based on team learning with the aim of guiding material development towards more sustainable products. The suggested process emphasises the material or product development team's need to understand which surrounding world and future-oriented considerations will have significant impacts on the specific product's sustainability performance.
\end{abstract}

Keywords: action research; team learning; guiding; material development; early product development; sustainability assessment.

Reference to this paper should be made as follows: Clancy, G., Fröling, M. and Svanström, M. (xxxx) 'Insights from guiding material development towards more sustainable products', Int. J. Sustainable Design, Vol. X, No. Y, pp.000-000. 
Biographical notes: Gunilla Clancy holds an MSc in Chemistry from Gothenburg University 1994 and is currently a PhD candidate at the Division of Chemical Environmental Science, Chalmers University of Technology. She has several years of industry experience, including having worked as Environmental Assessment Specialist at Akzo Nobel and Environmental Specialist within product development at IKEA of Sweden. During this time, she participated as an IKEA representative in the Center for Environmental Assessment of Product and Material Systems (CPM). The research focus for her $\mathrm{PhD}$ dissertation is on guiding development of wood-based materials towards more sustainable products.

Morgan Fröling is an Associate Professor in Ecotechnology and Environmental Science at Mid Sweden University. His research interests are in systems evaluation, especially of innovative energy or bio-based technical systems, and how we can optimise the use of at the same time as minimise negative impacts on ecosystem services when moving toward a more bio-based economy. $\mathrm{He}$ holds a MSc in Chemical Engineering and achieved his $\mathrm{PhD}$ in 2002 at Chalmers University of Technology.

Magdalena Svanström is an Associate Professor in Chemical Environmental Science at Chalmers University of Technology. After her PhD within Chemical Engineering at Chalmers in 1997, she did a PostDoc at Massachusetts Institute of Technology in 2001. Her current research interests are in life cycle assessment and broader sustainability assessment, in particular in early stages of product development, and focus areas include sludge management, district heat distribution and products from forest industry. She also has a research interest in education for sustainable development, in particular in important competences within engineering education. She is the Director of Chalmers Learning Centre.

\section{Introduction}

In order to stay in business in the long term, companies need to develop and offer more sustainable products. Achieving this involves many different considerations, such as impacts on the resource base, on climate, and other challenging aspects of human society. Since many sustainability features of a product is related to the materials that it is made of, directly or indirectly, it is of utmost importance to include sustainability considerations related to potential products even in early material development stages.

This article introduces an approach for guiding material development towards more sustainable products. Material development can be carried out as an early stage of a product development process but can also be performed before, after or in parallel to a product development process. The suggested approach has been developed as a response to the needs of a specific project (carrying out material development for an already existing product) but it is here described in a generalised way along with some activities performed in the project with the hope that it can provide useful input to other similar projects. The suggested approach is the outcome of using action research within the industry/university joint material development research project. The project aimed at developing wood-based materials to replace petroleum-based materials in absorbent hygiene products while ensuring that the product containing the new materials will be more sustainable than the present one. The project was thus based on the assumption that 
petroleum prices will continue to rise and that there will be increasing demands of more renewable materials in public procurement, and that a move towards renewable raw materials might therefore be a move towards a more sustainable product. A sustainability assessment subproject aimed to both guide the material development project towards a more sustainable product and assess goal fulfilment. The project was not a traditional product development project but rather a material development project at a very early stage; it aimed at modifying properties of wood fibres and transforming them into new materials with new properties that could be utilised in absorbent hygiene products. The material development team did therefore mostly consist of researchers and experts knowledgeable about chemical and physical modifications of wood fibres, materials in absorbent hygiene products and materials testing. However, with the goal that the materials should be able to make up part of a more sustainable product, appropriate product considerations had to be included also at this material development stage.

Manufacturers of currently used petroleum-based materials have over a long period of time successfully worked on the environmental optimisation of their processes and on the improvement of material properties. To develop a new material that performs better than the material to be replaced, taking into consideration all relevant sustainability aspects, is therefore expected to be a difficult task. However, improved performance in areas other than the environmental parameters that are conventionally measured may present compensatory effects that outweigh, for example, a slight increase in acidification potential or energy use. But, in order for this possible change in impacts to be considered, assessment methods capable of handling a view that is more holistic than the current one will have to be in place. Furthermore, an approach is needed that guides the material development team to greater awareness of such sustainability considerations in order to achieve more than just an optimisation of the current situation and to a rethink based on a more holistic view.

The methods that have been employed in guiding activities in the project build partly on insights gained and elements identified in a review of existing sustainability impact assessment tools that has been reported elsewhere (Clancy et al., 2013). That review focused, in particular, on opportunities for comparing the sustainability of the use of wood- and petroleum-based materials in products and it showed that available tools do not fulfil the requirements of handling this comparison. This is because of their (at least present) inability to deal with some potentially important aspects, such as social impacts, impacts on ecosystem services and biodiversity, and competition for different types of limited resources like petroleum, land area and water.

The results from the preceding study also reinforce the understanding that in an ongoing sustainability assessment aimed at guiding material development, a product life cycle perspective is nonetheless necessary, essential sustainability considerations must be developed and described from case to case, and assessment parameters need to be selected in relation to such a description. The study also showed that the description should not only address present sustainability concerns but also possible future concerns. Consequently, a specific challenge emerges in material development and early stages of product development since the product system is not yet fully defined. Therefore, a process that iteratively develops knowledge in three mutually dependent areas is needed. These three areas are: the design of the product system, the corresponding relevant sustainability assessment parameters, and the resulting sustainability performance of the product system, as illustrated in Figure 1. These points of departure are sometimes implicit in materials and product development but are seldom clearly stated and, 
therefore, often forgotten. In order to go beyond assessment and also provide guidance through this complex iterative process, team learning became an important tool, as has been suggested by several authors (Edmondson and Nembhard, 2009; Hardi and Zdan, 1997; ISO/TR 14062, 2002). In the present article, team learning refers to the process of working collectively in a group to achieve common objectives by acquiring, sharing and combining knowledge through working together, as discussed in further detail regarding effective team learning in organisations by Decuyper et al. in 2010.

Figure 1 Illustration of the iterative procedure advocated in outlining the product system, in selecting relevant assessment parameters for the system and in assessing the sustainability impact of the product

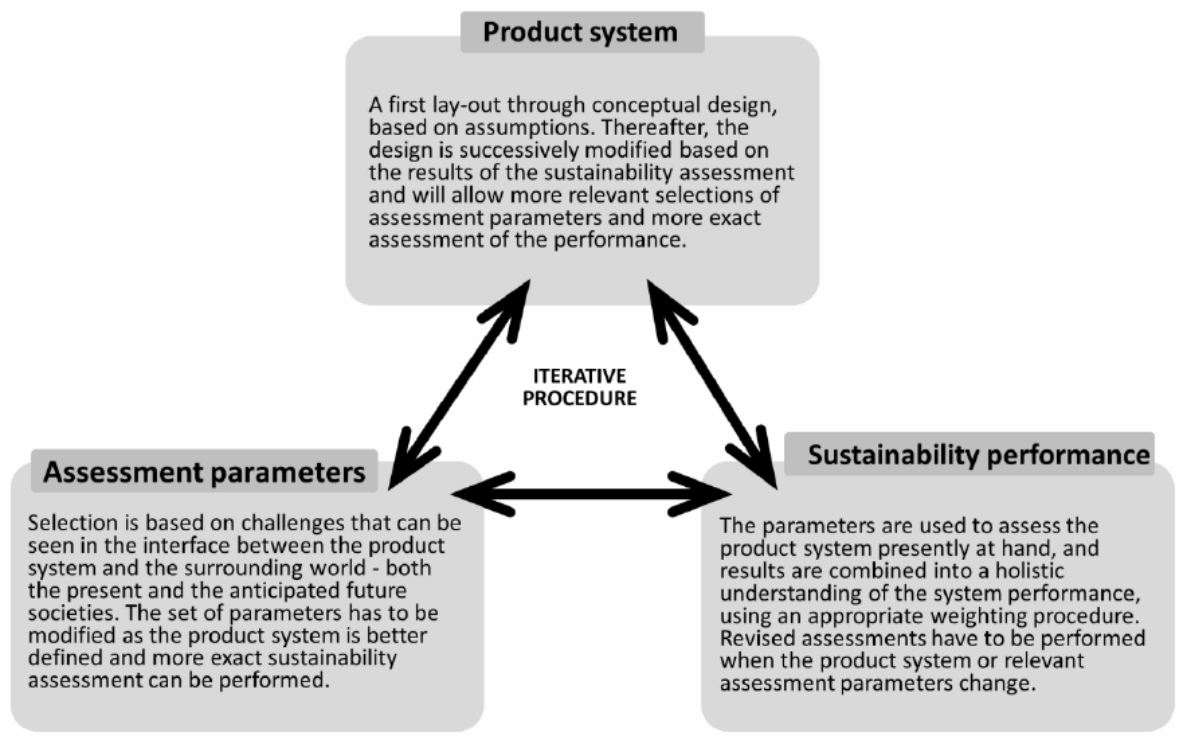

A number of concepts and tools, like ecodesign, design for environment, cleaner production and life cycle assessment (LCA) have been developed to make it possible to integrate environmental or sustainability aspects into different stages of product development (Karlsson and Luttropp, 2006; Wrisberg et al., 2002). These are generally constructed in such a way that they result in the environmental improvement of existing products and, consequently, they may result primarily in the optimisation of the current product system, e.g., by replacing product parts or processes representing major environmental impacts based on the industrial processes currently in use. Such approaches normally result in marginal improvements when compared with the present situation. This is not in itself bad, but since a more sustainable, future society may put very different demands on products than even the strictest environmental requirements of today, material development towards more sustainable products needs to be more holistic and future-oriented, i.e., based on a vision of the long-term sustainability of society and on an understanding of what challenges this poses to a product system that will potentially use the developed material. This difference in focus, on either optimisation or future-orientation, has been discussed by van Weenen (1997) in relation to sustainable product development. van Weenen concludes that future-orientation requires that the 
project team applies both a holistic perspective and a life cycle perspective in their considerations.

Several suggested approaches for integrating future-orientation into product development are based on applying the four principles for sustainability developed by Robèrt and Holmberg (Holmberg, 1998) in a four-step backcasting procedure in strategic planning towards sustainability (Holmberg and Robèrt, 2000):

a defining criteria for sustainability

b describing the current situation in relation to the criteria for sustainability

c envisaging future sustainable solutions

d finding strategies towards the solutions.

One such approach aims to develop and test the robustness of a business idea (Lundqvist et al., 2006), but its use in product development has not been described. Another approach has taken this one step further and has developed guiding questions to promote a holistic perspective in product development (Byggeth et al., 2007). As a complement to the guiding questions, and to provide an overview of major sustainability challenges and opportunities early on for the management and for the product development team, templates for sustainable product development have been proposed ( $\mathrm{Ny}$ et al., 2008). Both of these two later approaches require a facilitator to develop and/or choose the guiding questions since the product development team members themselves do not have the requisite knowledge. Consequently, the desired understanding needed for the material or product developers to continue making informed decisions for more sustainable products can probably not be achieved.

To develop new materials is in itself a complex task. To both realise and take into account which steps that can lead towards a product that contains the material and is more sustainable than competing products in the long term is even more challenging. Since decisions made in material development and early product development strongly affect the sustainability performance of the finished product, this can hardly be done effectively by anyone other than the material developers themselves. To end up with more than just marginal improvements of the current situation requires that the whole team is supported in developing an understanding of important sustainability concerns (present and future) in the same way as they take into consideration other performance criteria for the product. Since no approaches have been found in literature that are intended to guide early stages of material development that are aiming at an improved final product through these different concerns, this paper suggests a team-learning approach that has emerged from experiences of action research in a material development project in which the goal has been to make it possible to produce more sustainable products.

In the following section, the research methodology is presented and then, some guiding activities conducted in the project are described. Thereafter, reflections on experiences from the activities are given. Finally, a suggested team-learning process for guiding material development towards more sustainable products is described. 


\section{Research method}

In the following text and in the suggested process, the 'team' is defined as the group of people put together to develop the material or product and the 'sustainability assessor' is part of the team. The sustainability assessor facilitates the team process, searches for, compiles and presents the information the assessment can be based on and decides when to move on.

The action research conducted and the suggested process that is its outcome will here be described from the sustainability assessor's perspective. The action research was carried out during the first two years of a four-year material development project. The project was a collaboration between two companies and two university research groups. Both companies involved had a long tradition of working with environmental improvements and the safety of their products.

Action research means that the researcher tries to change or improve something in an ongoing project (in this case in guiding product development towards sustainability) and at the same time observes the process and its outcome. Action research involves utilising a systematic cyclical method of planning, taking action, observing, evaluating (including self-evaluation) and critical reflection prior to planning the next cycle (Wadsworth, 1998).

Each sustainability guiding activity was thoroughly planned, participants' reactions during the exercises were observed and the assessor's own experiences were noted, and the results were reflected on before subsequent exercises were designed. Different forms of feedback were generally requested directly after the activity, and sometimes spontaneous feedback was directly or indirectly achieved, either in connection to the activity or later on.

\section{Description of activities}

This section provides an overview of the main activities that were performed in the project in order to guide material development towards more sustainable products by using a team-learning approach.

\subsection{Setting the focus on the goal and on collaboration}

A kick-off meeting and an introductory course early on in the project involved discussions about collaboration, knowledge exchange, the project goal, the product under study and its main properties, the production process, and sustainable development. This created a sense of a shared goal and a joint mission, however, what sustainability means in practice for the specific material development project and how it may affect development in the project was not discussed in detail at the time.

\subsection{Exploring the challenges of sustainability assessment}

A multi-criteria analysis group exercise was carried out with the project team after only a few months in order to provide, at an early stage, an understanding of the general principles of the sustainability assessment and the issues that may arise. All groups ended up with a favourable result for the new product, indicating a common belief in the project 
idea. This exercise gave the team insight into how an assessment can be performed, what can be included in the assessment, what the uncertainties and difficulties are, and that the assessment is inevitably based on values and strongly dependent on the existing level of knowledge about potential impacts. The aspects that were selected by the different groups were similar and rather unspecific, including resources, waste, money and social aspects. The result of one multi-criteria analysis and comments on how it was made, is available elsewhere (Clancy, 2012).

\subsection{Describing sustainability and current unsustainabilities and developing visions of possible long-term solutions}

In a series of workshops, the sustainability concept was explored in order to provide meaning to the specific material development project; these activities were inspired by the backcasting approaches mentioned earlier. A discussion of what a sustainable society implies, in specific in relation to the considered target, was held and the agreement that emerged was documented as a mind map. As an inspiration in reflecting on whether important areas might have been missed in the mind map, the four principles of sustainability (Holmberg, 1998) were used. Each company then performed and presented a present state analysis of how different aspects of sustainability are violated today, throughout the value chain, focusing also on opportunities for the company to influence the situation. Thereafter, a brainstorming activity was performed in order to identify longterm solutions for the product that fulfil the agreed upon sustainability requirements. This activity made the team envision sustainable long-term solutions for the product function that go beyond the goal of the project in order to provide an understanding for what types of development in the project that may truly lead towards sustainability.

\subsection{Illustrating the environmental challenge of the task}

Results and conclusions of early cradle-to-gate LCA estimates of the new material were shown and discussed to enhance the understanding of the product system and the challenges in terms of different environmental parameters (Clancy et al., 2010b). The estimates showed that the presumed additional use of chemicals and energy for the new material may provide challenges in a comparison with presently used materials that have been technically and environmentally optimised over a long period of time. The estimates also showed that the minimisation of energy demand, in particular, is an important task in the project for reaching the goal of more sustainable products. Consequently, a large focus had to be put on minimising energy use in modification of the wood fibres but this also had to be combined with efforts to improve the performance in terms of other sustainability aspects to make up for a potentially larger energy use.

\subsection{Illustrating the challenges of increased use of renewable resources}

To enhance the understanding of possible long-term effects of increased wood resource use, an estimate of the wood resource use, if the new products were produced in large scale for the European market was made, with a projection to 2050. This was also recalculated into how much forest area this could potentially occupy (Clancy et al., 2010a). This exercise not only illustrated potential challenges of increased wood resource use but also illustrated the importance of considering both potential market shares and 
future societal development, and also highlighted methodological issues in terms of how increased fibre use can be translated into occupied land area.

\subsection{Listing available sustainability parameters}

An inventory of about 500 sustainability assessment parameters available in literature was compiled, both to provide a list to select useful parameters from and to find where the major gaps were in terms of the availability of parameters to cover the full range of potentially relevant sustainability aspects. The list, including references and comments on their use, is available elsewhere (Clancy, 2012). This inventory reinforced the understanding that we cannot rely on existing methods and ready-made sets of parameters, since there are severe gaps, particularly in for the project important areas such as land use and comparisons between renewable and non-renewable resources. The length of the list also highlighted the importance of deciding on and describing what are essential sustainability considerations for the specific case to limit the number of parameters to a manageable number for assessment. It is also important to narrow down the list to what is actually relevant for each specific project. Discussing the list in relation to the earlier work on the meaning of sustainability for the specific project illustrated challenges to the project team. Such challenges are further discussed for the case of petroleum- versus wood-based materials by Clancy et al. (2013).

\subsection{Discussing the importance and the usefulness of different sustainability parameters}

Selected sustainability aspects of relevance for the product were presented to the team by the assessor and each aspect's importance to the project was discussed. Examples of aspects that were intensely discussed are land occupation, the depletion of non-renewable resources, customer satisfaction with product function, competence development of co-workers, assets needed, e.g., the machinery to produce the new material, and working in a transparent way with stakeholders. For aspects that were deemed essential, assessable parameters were discussed. The exercise aimed at providing an understanding to the team of the different aspects and parameters that may be involved.

\subsection{Connecting the work of developers to properties of the product and to sustainability aspects}

When developing a material, it is important to understand which specific material properties are needed in order to deliver the desired product function, and how these affect the sustainability performance in different product life cycle stages. A workshop was performed with the aim of identifying the material properties (the material developer works at this level) with the strongest connection to the product function (the customer experiences the product at this level) and to different sustainability considerations (this is the level that the assessor operates on). The workshop focused on describing customer needs and sustainability aspects of the product and connecting these needs or aspects to material properties that the material developers work with in their daily activities. This was intended to give more clarity to the material developers about the properties to be improved and the reasons why. 


\subsection{Increasing the understanding of the dependence on world development}

To increase the understanding, in the team, of how developments in the world can affect the sustainability of a product, a scenario analysis was performed following the description by Lundqvist et al. (2006). External factors which may influence the final product were identified in a brainstorming activity. The identified factors were discussed and placed in a diagram based on their predictability (x axis) and on their potential impact on the sustainability of the final product (y axis), see Figure 2. Two highly unpredictable and highly impacting, but unrelated, factors were selected and used to produce a new diagram, varying these two from low to high to set up the axes. The four different future scenarios, represented by the quadrants in the new diagram, illustrated four very different future worlds that are reported elsewhere (Clancy, 2012). A robust strategy for the new product should be successful in all these different scenarios. The four different scenarios were explored by the team in order to provide an understanding of these requirements.

Figure 2 A summary of factors discussed when setting up future scenarios in the material development project (see online version for colours)

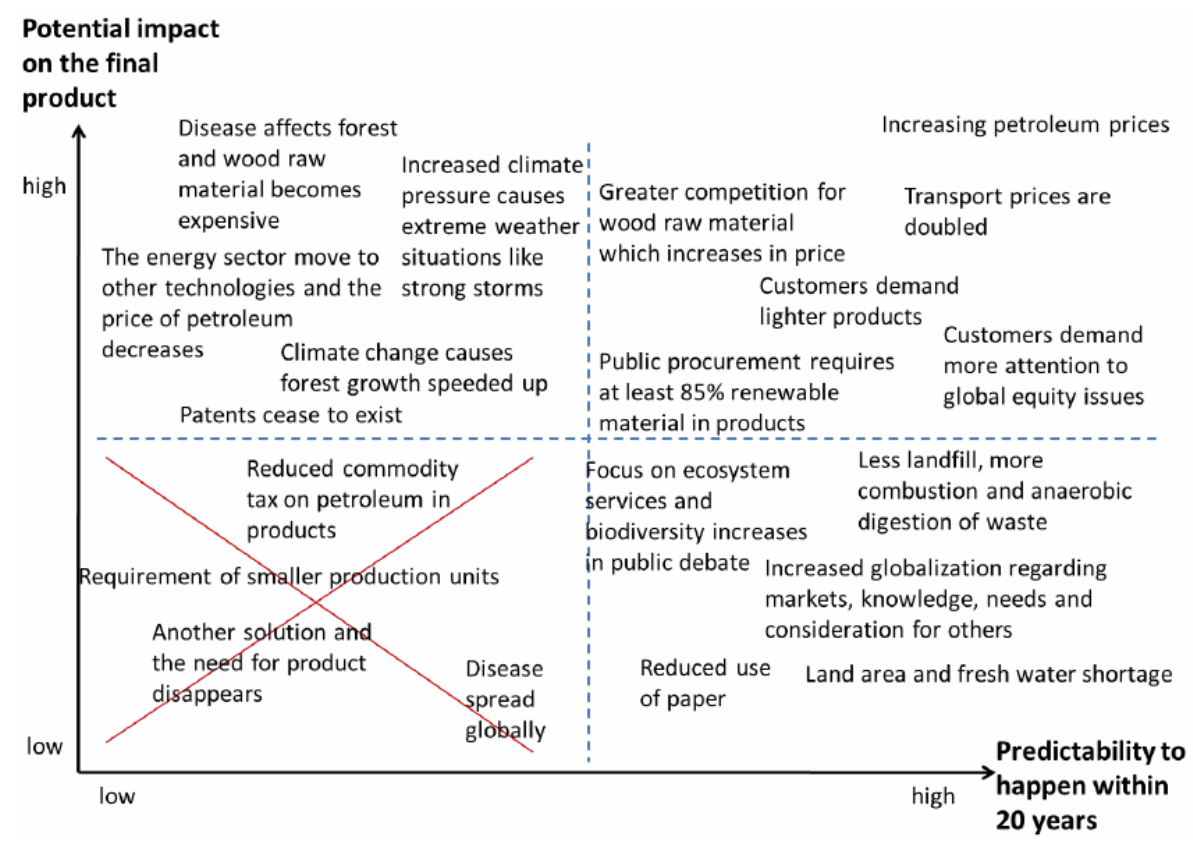

Note: See activity I in the text.

\subsection{Continuous considerations of potential sustainability impacts of new materials}

A material-checklist template was developed to help material developers continuously consider potential sustainability challenges and the opportunities of new materials at a very early stage. The material-checklist template and some comments on its use, is 
available elsewhere (Clancy, 2012). The checklist was intended to be used for every new material that was produced in laboratory scale within the project. However, since the checklist, like commonly used checklists in product development, mainly included social and ecological responsibilities in the supply chain, it provided no direct meaning to the material developers in their work. The checklist would have been more useful if parameters had been selected and described in a way that connected more strongly to properties that material developers could influence.

\subsection{Regular illustrations of the sustainability performance and potential trade-offs}

'Sustainability profiles', graphic representations of the considered aspects and the relative performance of the envisioned product using the new material in comparison to the reference for each aspect, were used to visualise the current overall performance of the new product. These profiles were updated regularly as more knowledge about the product system, relevant assessment parameters, and the resulting sustainability performance emerged. The profiles illustrated the progress in the project and which aspects that at each time constituted the greatest challenges, and they also highlighted the need for handling trade-offs in a structured and transparent way, see Figure 3 for an example of an early version.

Figure 3 Example of a 'sustainability profile' (used in activity K) with selected sustainability parameters, comparing a potential new product with the reference used in the project, presented as percentage relative to the highest contributor

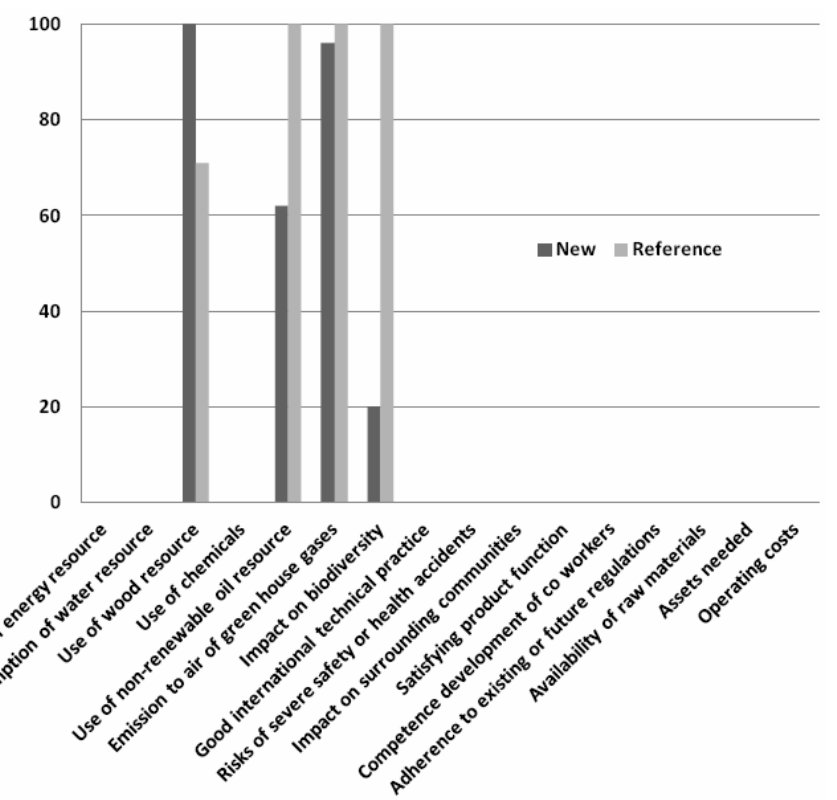

Note: During the process, more information will become available and be assessed, and gaps in the profile will be filled. 


\section{Reflections on experiences}

While performing the above-mentioned activities in an effort to iteratively develop an understanding of the sustainability performance of the emerging product system for the envisioned final product to support the guiding of the material development project (Figure 1), action research was carried out in order to develop methodologies to be used later in the ongoing project and, in a generalised way, also in other projects. Experiences from carrying out the activities, in particular barriers that hampered progress, will be reflected on here.

In projects in which several different organisations are involved, intellectual property issues and cultural clashes can be expected. In the project, participants indicated concern about sharing information. It can be speculated that when employees do not know what should be treated as a secret for intellectual property or other reasons, everything is treated as a secret to be on the safe side. Argyris and Schön (1989) talk about organisational defensive routines as any policy or practice that protects organisations from embarrassment or threat and at the same time prevents them from identifying and reducing the cause of embarrassment or threat. According to Argyris (1986), organisational defensive routines are anti-learning.

In the project, some resistance to guiding activities was experienced at an early stage, perhaps because of a fear that results could appear unfavourable. There were also occasions when individuals expressed a desire to know the results before the work had been carried out, presumably to ensure that the results would not challenge other ongoing activities. This can be seen as another example of organisational defensive routines as described above.

Many times throughout the chain of activities, it became apparent that the perceptions about the idea of the process and the roles of different participants varied greatly among team members. In hindsight, an initial inventory of the participants' perceived role in the process would have been beneficial in order to plan for modifying either the process or participants' perceptions of their role and of the process. Thus, in projects of this type, it would be useful to identify challenges to integrating learning and achieving change by learning more about the participants' different needs, their attitudes towards the project and their power to act, at an early phase in the project. One way to do this is by performing a stakeholder analysis (Bell and Morse, 2008).

Because of the major importance of decisions made by the material development team in developing a more sustainable product, efforts to describe the large impact that their decisions have on the sustainability of the final product to motivate them to participate in team-learning activities may be needed. Their important role in the task, as they make everyday decisions during the process that will strongly influence the sustainability of the product, must be demonstrated to them, and they need to be convinced that their efforts are requested by their organisation and will be rewarded and appreciated.

The lessons learned from reflecting on activities within the project were used, together with ideas and findings from literature, in putting together a suggested process for guiding material development when the goal is to achieve more sustainable products. The suggested process can function as support to the assessor in setting up more detailed activities in different types of projects with more sustainable products as an overall goal. Inspiration to specific activities may be found in the descriptions provided earlier in this 
paper, but activities must be tailor-made to suit the needs and opportunities of each specific project.

\section{Suggested process for guiding material development towards more sustainable products}

Material developers strongly affect the sustainability performance of a product utilising the material. To make it possible for them to make choices towards a more sustainable final product, and if needed, even rethink the material idea based on more holistic considerations, developers need to be aware of and fully grasp which surrounding world and future-oriented considerations that may make significant impacts on the envisioned product's sustainability performance. It is not enough to provide developers with a list of parameters, e.g., acidification potential and global warming potential, with values that need to be lowered. They also need support in translating and integrating the parameters into something that can guide them in their individual area of expertise and in developing a more holistic understanding of the product system. This is the background to the suggested learning process described below, aimed at being performed continuously throughout the project. The need to address different actors' specific needs in performing and communicating sustainability assessments was highlighted by Löfgren (2012) in a doctoral thesis.

To be able to motivate participation in the process, it is important that the assessor understands the role of each of the project members and their expectations on the project. This understanding is necessary for the assessor to be able to communicate with the participants and to set up an appropriate process. A stakeholder analysis or similar analysis, giving insight into which roles the participants expect to take in the project and what they expect from the assessor, is therefore highly recommended to do before the work starts, and will most probably result in a more successful project. The assessor needs to be viewed as and involved as an advisor and a facilitator in the process and not seen as someone who will only check that requirements are fulfilled. This is both to make sure that a participatory team learning process takes place and that the assessment parameters and the assessment results are iteratively refined throughout the project based on the increasing knowledge about the product system. Our experience from different projects is, however, that often, an assessor's role is to control that a change is towards a more sustainable situation rather than to help developers manoeuvre through a challenging task. Furthermore, the risk of encountering different organisational defensive routines should always be kept in mind when planning and carrying out the project. It may also be helpful if the process is briefly outlined for the team before it is started and that each team member commits to participating in the process.

\subsection{Defining the long-term goal and determining scope}

The first step of the suggested process is to make the whole project team aware of the considerations that may have a significant impact on the specific product's sustainability as seen from a holistic and future-oriented perspective. This is illustrated in Figure 4 as defining the long-term goal and determining scope. This could alternatively be performed by the management; it is then vital that they hand the descriptions of goal definition and limitations over to the project team in an incisive way. 
Figure 4 The suggested process for guiding material development projects towards more sustainable products

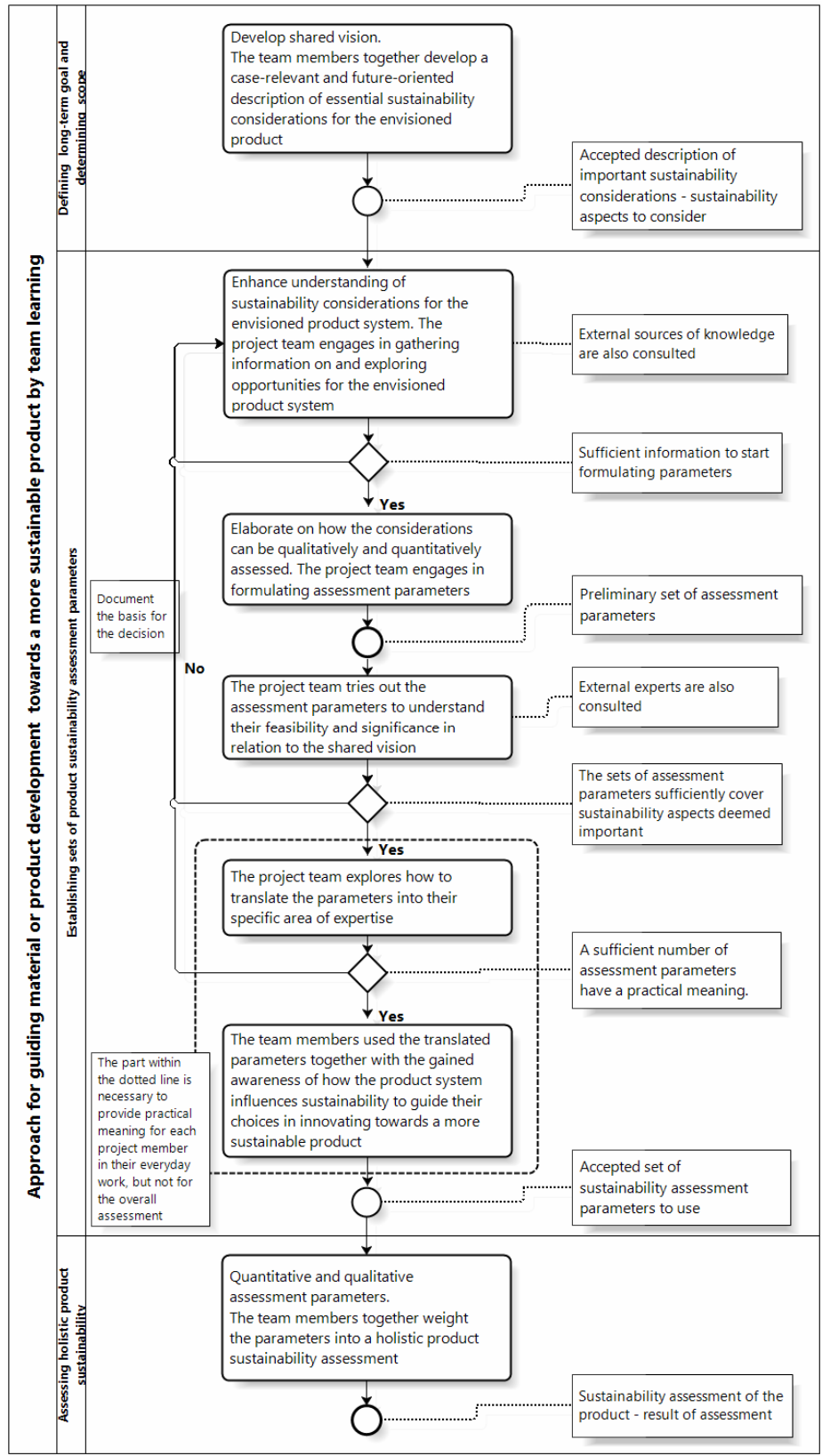

Notes: Through team involvement during material or product development, a shared goal and relevant sets of product sustainability assessment parameters for a specific product are established. Note that the whole process is lead by a sustainability assessor in an iterative process, but such features are excluded from the scheme for clarity reasons. 
A shared vision is needed both to define the target and the scope for the material or product development process and for efficient intra-project communication (Hong et al., 2011; Lackus and Kolar, 2007). If the goal of a project is to obtain 'a more sustainable final product', then visualising and describing what the qualities of this 'more sustainable final product' can be are vital. This should be done by the whole project team, together with other important stakeholders, in order to make sure that knowledge from many different areas and multiple points of view are included in the process. The project team members can then increase their awareness of important considerations and develop an understanding and acceptance of the project's description of a 'sustainable final product'. When the description of the goal is developed together, a common language will evolve that will enable more effective intra-project communication.

In developing the description of a more sustainable product for the project, an appropriate time-frame for the specific product must be applied and uncertainties about future developments in society must be handled in a satisfactory way. Approaches are available that handle such uncertainties as well as how the product affects and is affected by the surrounding world, such as the activities ' $\mathrm{C}$ ' and ' $\mathrm{I}$ ' described above. In applying these approaches, it could be useful to aim for reformulating a problem in a variety of different ways and not only focus on coming up with as many ideas as possible of one problem, as in ordinary brainstorming. Such reformulating of a problem is called ‘brainfiring’ by Härén (2004).

In Figure 4, 'sustainability aspects' refer to areas such as biodiversity, climate, safety and health, operational cost, availability of raw material, and other areas of sustainability that may be influenced by choices made in material or product development. The project's case-specific description of 'sustainable final product' should include the areas that need to be assessed - the relevant product sustainability aspects - and how to handle trade-offs between these areas as well as uncertainties and data gaps. This description will form the goal and scope for the development project, and for the assessment work. The description should be revised when needed, i.e., with changes in circumstances or new knowledge. The suggested process, therefore, is set up to allow for going back and adjusting the direction of development, i.e., iterating.

\subsection{Establishing sets of sustainability parameters}

Each sustainability aspect identified in the first step can be described by one or several 'assessment parameters'. The second step in guiding towards a more sustainable final product is to establish sets of relevant assessment parameters in a team-learning process, including translating the assessment parameters into parameters that are relevant for the participants' specific tasks. This last step of translating the parameters is an act of inviting the team to find out how they in their work affect product sustainability instead of telling them what to improve or to avoid in terms not clearly connected to their work, which is what is conventionally done. If the parameters are not integrated into something that is meaningful in relation to each participant's expertise and everyday work, the participants cannot utilise their skills towards the goal of a more sustainable final product since they lack direction.

In the suggested process (Figure 4), the part of establishing sets of sustainability parameters is divided into several sub-steps. First, information about the identified sustainability aspects is gathered by the assessor for the product's entire life cycle (the product system) from literature, stakeholders and experts. The assessor is advised and 
assisted by the project team. The information is then refined by the assessor and presented to the team, for example by using estimates and statistics as in the activities ' $D$ ' and ' $E$ ' described above.

To avoid overlooking relevant parameters, the preliminary sets (plural because there may be different sets for different scenarios or team members) of assessment parameters should be reviewed both by employees with other expertise within the company and by external experts. Examples of external experts are scientists in the field, or representatives from trade organisations or non-governmental organisations. The sets should also be evaluated in relation to the coverage of the sustainability aspects deemed important in the project and also in terms of significance and the feasibility of assessing the parameters. Two activities described above, ' $F$ ' and ' $G$ ', are examples of how a team can evaluate and explore parameters.

If a set of assessment parameters is found not to sufficiently cover the sustainability aspects deemed important, then iteration is needed. If sufficient, the identified sustainability assessment parameters should be explored; ways of translating and integrating them into each team member's specific area of expertise and everyday work should be discussed. In practice, this can be done as described above for activity ' $H$ '. It is vital for guiding product development towards a more sustainable product that the project team not only understands and accepts the assessment parameters but that they can relate to them in their daily work. When the project team develops knowledge of how their daily work impacts the sustainability of the final product, the opportunity to make decisions towards an improved result becomes greater. If it is difficult to improve the performance of the envisioned product for the selected parameters, then the knowledge of holistic and future-oriented considerations acquired when defining the long-term goal and determining scope can be a base for rethinking the material idea and coming up with new ways of improving the sustainability of the final product.

\subsection{Holistic assessment of product sustainability}

When sets of sustainability assessment parameters have been agreed on, an assessment of the impact of the product system(s) can be performed. Reaching agreement and acceptance within the project team of the relative weights of different parameters should be less complicated when everyone has been involved in the process of establishing the sets of sustainability parameters. In other words, different views, or value-systems, should have appeared, been discussed and taken into account earlier on in the process. Different value-systems can also be applied in weighting in order to illustrate the potential effect on the final result, to enable a more holistic understanding of the implications of the results. Product sustainability assessment should be performed several times during a material or product development process to provide input to an, by necessity, iterative process, as described in Figure 1 . The activity ' $\mathrm{K}$ ' described above gives an example. The assessment is improved with the new knowledge gained of the product system and of relevant sustainability parameters each time it is performed. This type of assessment, where a wider systems perspective is reflected on, is only sparsely discussed in literature and more research is needed (Clancy et al., 2013), whereas data inventory and weighting procedures are thoroughly discussed in the literature (e.g., European Commission, 2009; Finnveden, 1999; Finnveden et al., 2009; Pennington et al., 2004; Rebitzer et al., 2004). To obtain a greater understanding of possible interpretations 
of the result, the whole team should be involved in establishing and exploring the weighting in the suggested process.

To sum up, the suggested process (Figure 4) for guiding material and product development projects towards more sustainable products emphasises the joint learning process of the team - with a specific focus on facilitating innovation towards more sustainable products by translating and integrating significant product sustainability characteristics into each team member's specific area of expertise and everyday work. The simultaneous use of external expertise, like stakeholders, NGOs and scientists, is crucial in order not to miss important views and knowledge. One goal is that this process leads to continuous knowledge enhancement throughout the product development process and to the reporting and discussion of results within the team. This is an iterative process which should continue until the product is available for sale, allowing the product sustainability parameters to be modified during the process to include new knowledge. The learning potentially achieved in a process like this will also be useful in later projects and may therefore create valuable spin-off effects.

\section{Concluding remarks}

Insights from a project aimed at providing new materials for an envisioned product and to ensure that the envisioned final product also becomes more sustainable were used to outline a team learning approach to guide such processes. To fully utilise the competence of the material developers in direction of sustainability, the whole project team needs to understand how considerations in their everyday development work can affect an envisioned product's sustainability performance. Guiding a material development project towards more sustainable products requires relevant and future-oriented assessment parameters that also must be translated into parameters that are meaningful for the material developers in their everyday work. This can be facilitated by a team learning approach, where these issues are jointly explored by the project team, e.g., by workshops connecting material properties and sustainability aspects of the product.

\section{References}

Argyris, C. (1986) 'Reinforcing organizational defensive routines: an unintended human resources activity’, Human Resource Management, Vol. 25, No. 4, pp.541-555.

Argyris, C. and Schön, D.A. (1989) 'Participatory action research and action science compared: a commentary', American Behavioral Scientist, Vol. 32, No. 5, pp.612-623.

Bell, S. and Morse, S. (2008) Sustainability Indicators Measuring the Immeasurable?, Earthscan, London, UK.

Byggeth, S., Broman, G. and Robèrt, K.H. (2007) 'A method for sustainable product development based on a modular system of guiding questions', Journal of Cleaner Production, Vol. 15, No. 1, pp.1-11.

Clancy, G. (2012) 'Guiding development of wood-based materials for more sustainable products', Chemical and Biological Engineering, Chalmers University of Technology, Göteborg, Sweden.

Clancy, G., Fröling, M. and Svanström, M. (2010a) 'The ageing society: an example of consequences for biomass use', MFA-ConAccount Meeting 'MFA for Sustainable Future', Tokyo, Japan. 
Clancy, G., Fröling, M., Peters, G.M. and Svanström, M. (2010b) 'Environmental challenges when developing renewable materials to replace non-renewable materials - guidance from LCA studies', EcoBalance 'Towards \& Beyond 2020', Tokyo.

Clancy, G., Fröling, M. and Svanström, M. (2013) 'Changing from petroleum to wood based materials: critical review of how product sustainability characteristics can be assessed and compared', Journal of Cleaner Production, Vol. 39, pp.372-385.

Decuyper, S., Dochy, F. and Van den Bossche, P. (2010) 'Grasping the dynamic complexity of team learning: an integrative model for effective team learning in organisations’, Educational Research Review, Vol. 5, pp.111-133.

Edmondson, A.C. and Nembhard, I.M. (2009) 'Product development and learning in project teams: the challenges are the benefits', Journal of Product Innovation Management, Vol. 26, No. 2, pp.123-138.

European Commission (2009) ILCD Handbook: Analysis of existing Environmental Impact Assessment methodologies for use in Life Cycle Assessment (LCA), Background document, System, I.R.L.C.D. (Ed.).

Finnveden, G. (1999) A Critical Review of Operational Valuation/Weighting Methods for Life Cycle Assessment, AFR-report (AFN, Ed.): Swedish Environmental Protection Agency, Stockholm, Sweden.

Finnveden, G., Hauschild, M.Z., Ekvall, T., Guinée, J., Heijungs, R., Hellweg, S., Koehler, A., Pennington, D. and Suh, S. (2009) 'Recent developments in life cycle assessment', Journal of Environmental Management, Vol. 91, No. 1, pp.1-21.

Hardi, P. and Zdan, T. (1997) Assessing Sustainable Development: Principles in Practice, International Institute for Sustainable Development, Winnipeg, Canada.

Härén, F. (2004) The Idea Book, Interesting Books, Stockholm.

Holmberg, J. (1998) 'Backcasting: a natural step when making sustainable development operational for companies', Greener Management International, No. 23, pp.30-51.

Holmberg, J. and Robèrt, K.H. (2000) 'Backcasting - a framework for strategic planning', International Journal of Sustainable Development and World Ecology, Vol. 7, No. 4, pp.291-308.

Hong, P., Doll, W.J., Revilla, E. and Nahm, A.Y. (2011) 'Knowledge sharing and strategic fit in integrated product development projects: an empirical study', International Journal of Production Economics, Vol. 132, No. 2, pp.186-196.

ISO/TR 14062 (2002) Environmental Management - Integrating Environmental Aspects into Product Design and Development, International Organization for Standardization, Geneva, Switzerland.

Karlsson, R. and Luttropp, C. (2006) 'EcoDesign: what's happening? An overview of the subject area of EcoDesign and of the papers in this special issue', Journal of Cleaner Production, Vol. 14, Nos. 15-16, pp.1291-1298.

Lackus, M. and Kolar, M. (2007) 'Investigation into company specific design structure to rise design awareness', Nordic Design Research Conference 'Design Inquiries', Stockholm, Sweden.

Löfgren, B. (2012) The Green Engineer as an Enabler of Life-Cycle Management in Manufacturing: Models and Practices, Department of Energy and Environment, Chalmers University of Technology, Göteborg.

Lundqvist, U., Alänge, S. and Holmberg, J. (2006) Strategic Planning Towards Sustainability - An Approach Applied on a Company Level, Chalmers University of Technology, Göteborg.

Ny, H., Hallstedt, S., Robért, K.H. and Broman, G. (2008) 'Introducing templates for sustainable product development: a case study of televisions at the Matsushita Electric Group', Journal of Industrial Ecology, Vol. 12, No. 4, pp.600-623.

Pennington, D.W., Potting, J., Finnveden, G., Lindeijer, E., Jolliet, O., Rydberg, T. and Rebitzer, G. (2004) 'Life cycle assessment Part 2: current impact assessment practice', Environment International, Vol. 30, No. 5, pp.721-739. 
Rebitzer, G., Ekvall, T., Frischknecht, R., Hunkeler, D., Norris, G., Rydberg, T., Schmidt, W.P., Suh, S., Weidema, B.P. and Pennington, D.W. (2004) 'Life cycle assessment Part 1: framework, goal and scope definition, inventory analysis, and applications', Environment International, Vol. 30, No. 5, pp.701-720.

van Weenen, H. (1997) 'Sustainable product development: opportunities for developing countries', Industry and Environment, Vol. 20, Nos. 1-2, pp.14-18.

Wadsworth, Y. (1998) What is Participatory Action Research?, Action Research International, Paper 2 [online] http://www.aral.com.au/ari/p-ywadsworth98.html (accessed 20 March 2013).

Wrisberg, N., Udo de Haes, H.A., Triebswetter, U., Eder, P. and Clift, R. (2002) Analytical Tools for Environmental Design and Management in a Systems Perspective, Kluwer Academic Publishers, Dordrecht, The Netherlands. 